$$
\text { CONF-970135-- }
$$

\title{
Wind Tunnel Calibration of 5-Hole Pressure Probes for Application to Wind Turbines
}

\section{RECEIVED JUN 181998 Q. $8 . T 1$}

L.J. Fingersh

M.C. Robinson

National Wind Technology Center

National Renewable Energy Laboratory

Presented at

ASME/AIAA Wind Energy Symposium

Reno, $N V$

January 6-9, 1997

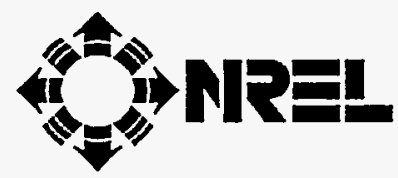

National Renewable Energy Laboratory 1617 Cole Boulevard

Golden, Colorado 80401-3393

A national laboratory of the U.S. Department of Energy Managed by Midwest Research Institute for the U.S. Department of Energy under contract No. DE-AC36-83CH10093

MASTER

Work performed under task number WE711120

May 1998

DISTRIBUTION OF THIS DOCUMENT IS UNLAMTED 


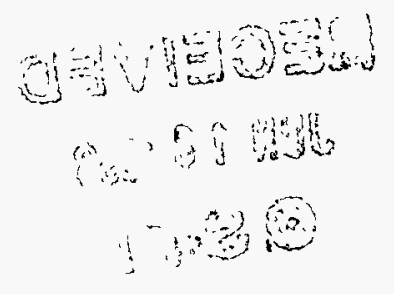

NOTICE

This report was prepared as an account of work sponsored by an agency of the United States government. Neither the United States government nor any agency thereof, nor any of their employees, makes any warranty, express or implied, or assumes any legal liability or responsibility for the accuracy, completeness, or usefulness of any information, apparatus, product, or process disclosed, or represents that its use would not infringe privately owned rights. Reference herein to any specific commercialproduct, process, or service by trade name, trademark, manufacturer, or otherwise does not necessarily constitute or imply its endorsement, recommendation, or favoring by the United States government or any agency thereof. The views and opinions of authord expressed herein do not necessarily state or reflect those of the United States government or any agency thereof.

Available to DOE and DOE contractors from:

Office of Scientific and Technical Information (OSTI)

P.O. Box 62

Oak Ridge, TN 37831

Prices available by calling (423) 576-8401

Available to the public from:

National Technical Information Service (NTIS)

U.S. Department of Commerce

5285 Port Royal Road

Springfield, VA 22161

(703) 487-4650 


\section{DISCLAIMER}

Portions of this document may be illegible electronic image products. Images are produced from the best available original documerit. 

TURBINES

\author{
L. J. Fingersh, M. C. Robinson \\ National Renewable Energy Laboratory \\ National Wind Technology Center \\ Golden, Colorado
}

\begin{abstract}
A method to quantify the local inflow vector on a rotating turbine blade using a 5-hole static pressure probe was developed at the National Wind Technology Center. The technique-permits quantification of dynamic pressure, angle-of-attack and cross-flow-angle to magnitudes of $\pm 40^{\circ}$ in any inflow direction parallel to the probe centerline. A description of the static and dynamic calibration procedure, iteration sequence for data reduction, and field results are included.

\section{$\underline{\text { Nomenclature }}$}

\begin{tabular}{|c|c|}
\hline $\begin{array}{l}\mathrm{p}_{\mathrm{j}} \\
\mathrm{C} \mathrm{p}_{\mathrm{c}}\end{array}$ & $\begin{array}{l}\text { local probe static pressure }(j=1 \text { to } 5) \\
\text { center tap pressure coefficient } \\
\text { [ol-p }] a\end{array}$ \\
\hline$\Delta \mathrm{Cp}_{\alpha}$ & $\begin{array}{l}\text { [p1-p.] / } q_{\text {. }} \\
\text { differential pressure coefficient, } \alpha \text { plane }\end{array}$ \\
\hline$\Delta \mathrm{Cp}_{\theta}$ & $\begin{array}{l}\text { differential pressure coefficient, } \theta \text { plane } \\
\text { [p2-p3 ] } / q_{\text {. }}\end{array}$ \\
\hline q. & $\begin{array}{l}\text { free stream dynamic pressure } \\
1 / 2 p_{-} V_{-}^{2}\end{array}$ \\
\hline$P_{\text {_ }}$ & $\begin{array}{l}\text { free stream air density } \\
\text { free stream velocity }\end{array}$ \\
\hline
\end{tabular}
\end{abstract}

Introduction

Obtaining an accurate prediction of aerodynamic rotor performance is key to wind turbine design. The effects of design permutations in airfoil shape, solidity, twist and taper are evaluated using empirical codes based on momentum theory and 2-D wind tunnel empirical data. Such analyses fail to accurately model performance of the airfoils in the highly 3-D, turbulent and unsteady operating environment of an ordinary wind turbine.

In order to better characterize both the turbine inflow environment and the resulting dynamic effects on a real turbine, the National Renewable Energy Laboratory has instrumented a special wind turbine that is capable of measuring inflow, blade surface pressures and machine structural response. The "Unsteady Aerodynamics Experiment" has been in operation since 1988 and has helped characterize 3-D unsteady aerodynamics and peak structural loads. . $^{\text {th }}$

This paper is declared a work of the U.S. Government and is not subject to copyright protection in the United States.
Transient rotor loading is a consequence of the stochastic inflow. Fluctuations in both wind magnitude and direction directly affect the local blade aerodynamics. The primary driver for most of this unsteady aerodynamic phenomenon is a rapid change in local blade angle-of-attack through the static stall angle. ${ }^{3-4}$ In the past, angle-of-attack was measured on the turbine by employing a flow-angle flag mounted about one chord ahead of the blade. This flag provides accurate low-frequency angle-of-attack measurements but cannot respond quickly enough to measure unsteady response. Due to this limitation, other types of flowangle sensors were investigated as replacements for the flags. Differential pressure probes were found to be rugged and possessed sufficient frequency response for this application

Initially, several types of pressure-based sensor methods were considered. Ultimately a 5-hole, nearly conical pressure probe was selected because of it size, commercial availability and ability to measure crossflow-angle as well as angle-of-attack. This paper focuses on the comprehensive static and dynamic windtunnel calibration of the particular 5-hole probes selected and provides some preliminary measurements taken in the field.

\section{Methodology}

Wind turbines are subjected to a harsh aerodynamic environment. High turbulence, rapid angle-of-attack fluctuations, substantial cross-flow and very wide ranges in angle-of-attack are common. In order to fully characterize this environment, the probes were calibrated over $\mathrm{a} \pm 40^{\circ}$ angle-of-attack and cross-flowangle range. Additionally, the probes were dynamically calibrated at five reduced sinusoidal oscillation frequencies to check dynamic response capability.

\section{Static Calibration}

The 5-hole probe selected for evaluation was a United Electric Controls Company USD-F-312 DC 250 3-D flow-angle probe shown in Figure 1. The desired measured flow parameters $\left(q_{\ldots}, \alpha\right.$ and $\left.\theta\right)$ are obtained from three separate static calibration surfaces: 1) the center tap pressure coefficient $\left(\mathrm{C}_{\mathrm{c}}\right)$ as a function of differential pressure coefficients in the angle-of-attack $\left(\Delta \mathrm{C} \mathrm{p}_{\mathrm{a}}\right)$ and cross-flow $\left(\Delta \mathrm{Cp}_{\mathrm{y}}\right)$ planes, 2$)$ angle-of-attack 
$(\alpha)$ as a function of $\Delta \mathrm{CP}_{\alpha}$ and $\Delta \mathrm{Cp}_{\theta}$, and 3) crossflow-angle $(\theta)$ as a function of $\Delta \mathrm{Cp}_{\mathrm{a}}$ and $\Delta \mathrm{Cp}_{\mathrm{p}_{\theta}}$. The method of obtaining instantaneous values for $\mathrm{q}_{\mu}, \alpha$ and $\theta$ from the five measured static pitot pressures and the three calibration curves will be addressed later.

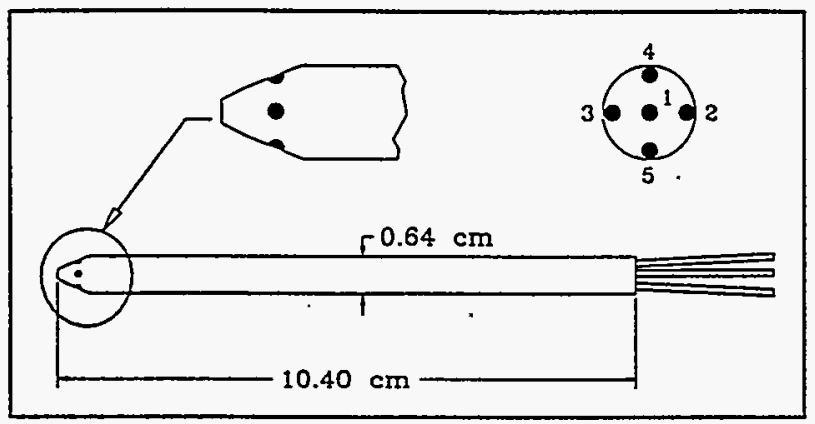

Figure 1 - 5-hole probe

The calibration surfaces for the center tap pressure, $\alpha$ and $\theta$ were determined empirically from wind tunnel data collected in the $3 \times 3 \mathrm{ft}$ low speed wind tunnel at the United States Air Force Academy. Five different probes were calibrated both statically and dynamically using the tunnel's dynamic pitch mount. Each pitot probe was mounted in the center of the test section and yawed through $\pm 40^{\circ}$. The Reynolds numbers and reduced frequencies tested are shown in Table 1. These values correspond to the anticipated values expected in field operations of the wind turbine. Calibration for cross-flow-angle and angle-of-attack was obtained by repeating the test with each probe rolled to $0^{\circ}, 15^{\circ}, 30^{\circ}$, $45^{\circ}, 60^{\circ}, 90^{\circ}, 120^{\circ}, 135^{\circ}, 150^{\circ}$. All pressures were normalized by tunnel $q$. Measured $\alpha$ and $\theta$ for the different roll angles were obtained by a simple coordinate transformation from the fixed tunnel to the probe reference geometry.

Table 1. Dynamic Wind-Tunnel Test Conditions.

\begin{tabular}{|c|c|c|}
\hline Frequency & Tunnel Speed & Reduced Frequency \\
\hline $0.83 \mathrm{~Hz}$ & $26.2 \mathrm{~m} / \mathrm{s}$ & 0.05 \\
\hline $2.83 \mathrm{~Hz}$ & $26.2 \mathrm{~m} / \mathrm{s}$ & 0.17 \\
\hline $5 \mathrm{~Hz}$ & $26.2 \mathrm{~m} / \mathrm{s}$ & 0.30 \\
\hline $5 \mathrm{~Hz}$ & $17.4 \mathrm{~m} / \mathrm{s}$ & 0.45 \\
\hline $5 \mathrm{~Hz}$ & $13.1 \mathrm{~m} / \mathrm{s}$ & 0.60 \\
\hline
\end{tabular}

Details of the tunnel pitch system and the pressure data acquisition system with system error analysis have been previously reported. ${ }^{5}$ In order to help eliminate any inherent system errors, the entire pressure measurement system used on the actual turbine including hardware, geometry (tube lengths, etc.) and data acquisition and storage systems was also used to perform this calibration and evaluation of the methodology.
Figures 2 and 3 are typical of the data obtained for each test condition. A plot of the $C_{p_{c}}$ and $\Delta C_{p_{\theta}}$ as a function of $\theta$ are shown in Figures 2 and 3, respectively. For both figures, the $\pm 40^{\circ}$ calibration pitch angle was in the $\theta$ (cross flow) plane. In Figure 2, the normalized center tap pressure ratio equals 1.0 at the stagnation point (around $\theta=0^{\circ}$ ) and diminishes at higher and lower angles. The response is not perfectly centered, reflecting machining asymmetries in the pressure port location. In Figure 3 , the normalized differential pressure achieves 0 at the stagnation point (around $\theta=$ $0^{\circ}$ ). Note that the cross-flow-angle is not linear with differential pressure over large angles and the differential pressure response is not quite 0 at the stagnation point.

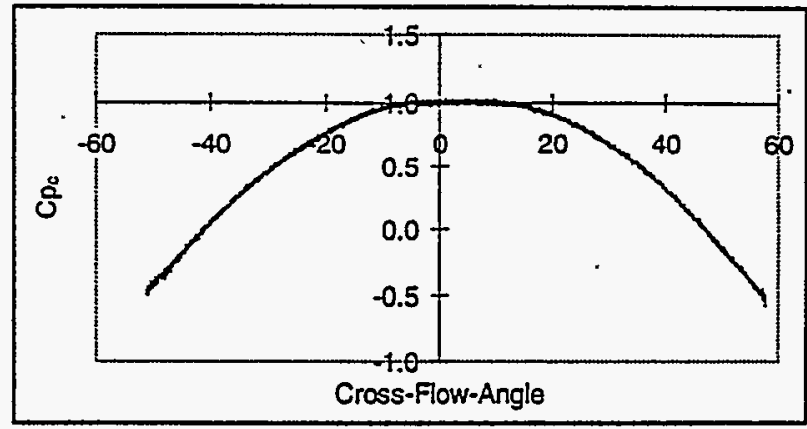

Figure 2 - Static calibration of total pressure ratio

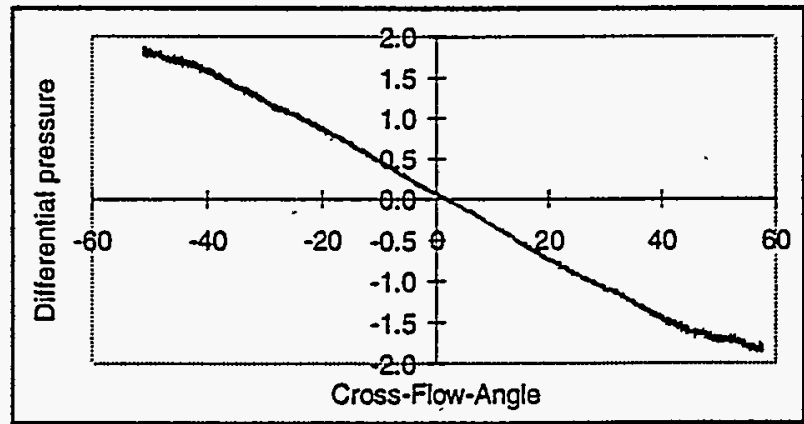

Figure 3 - Static calibration of spanwise-flow-angle. Angle-of-attack calibrations look similar.

In order to completely quantify the probe's response for any combination of $\alpha$ and $\theta$, a series of curves similar to Figures 2 and 3 were produced for each roll angle. Figures $4 \mathrm{a}, 5 \mathrm{a}$, and $6 \mathrm{a}$ show the values for $\mathrm{Cp}_{\mathrm{c}}, \alpha$ and $\theta$ as a function of $\Delta C \mathrm{p}_{\alpha}$ and $\Delta C \mathrm{p}_{\theta}$ respectively. Each roll angle appears as a single calibration line which runs along a contoured surface. A complete characterization of the surface was necessary in order to attain a usable probe calibration tool suitable for data reduction. 

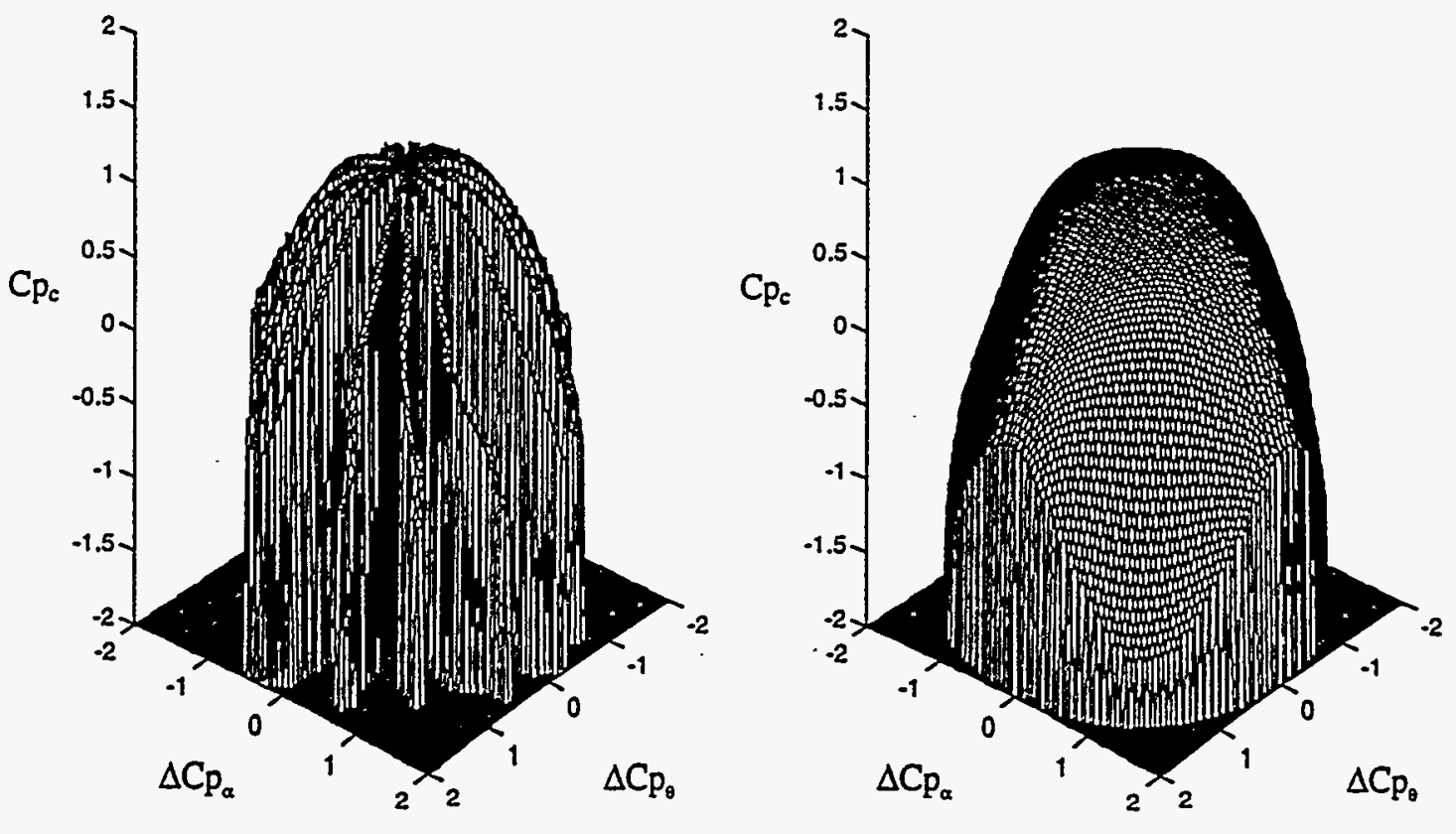

Figure 4 - Static calibration of dynamic pressure surface
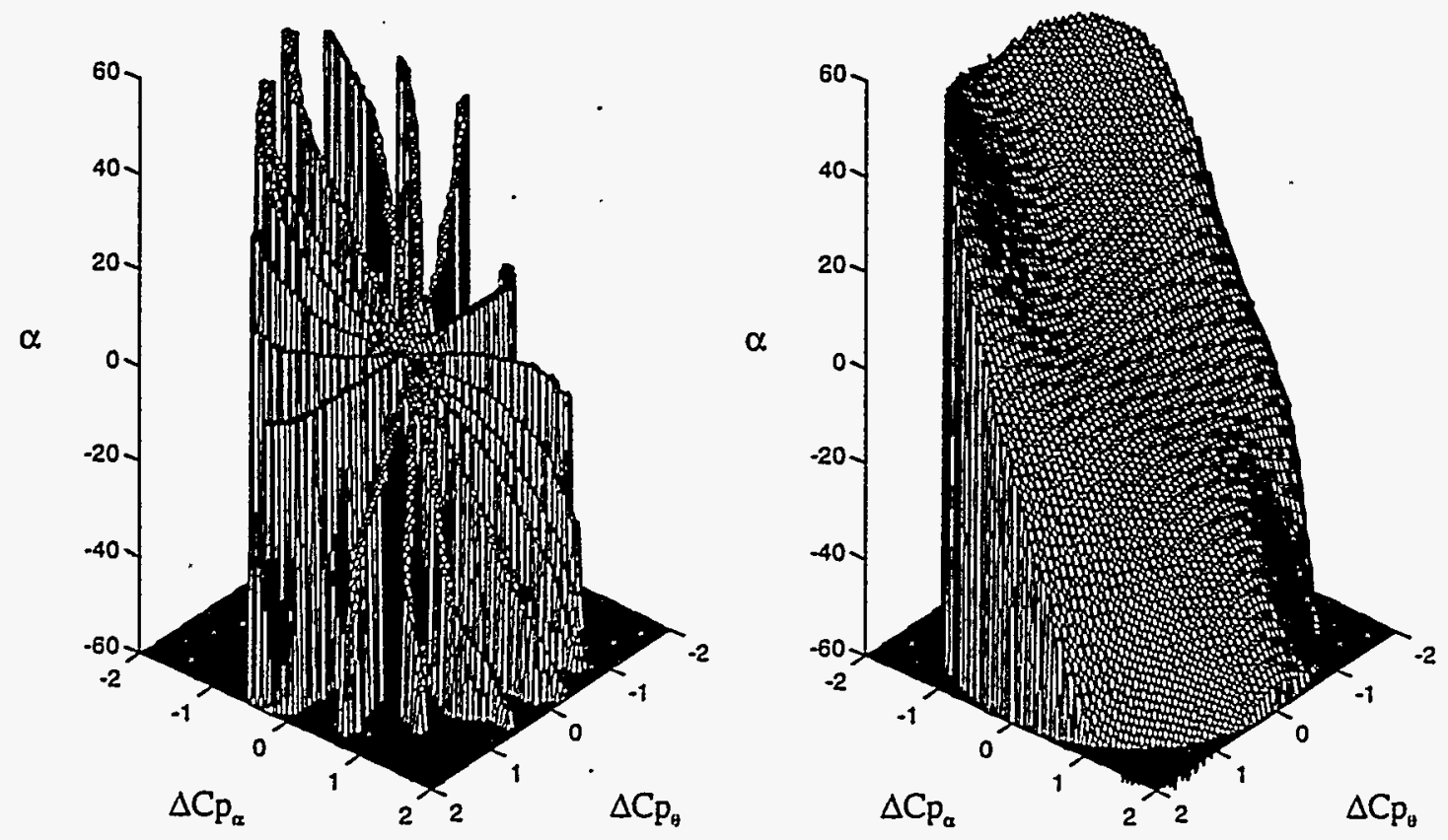

Figure 5 - Static calibration of angle-of-attack surface 

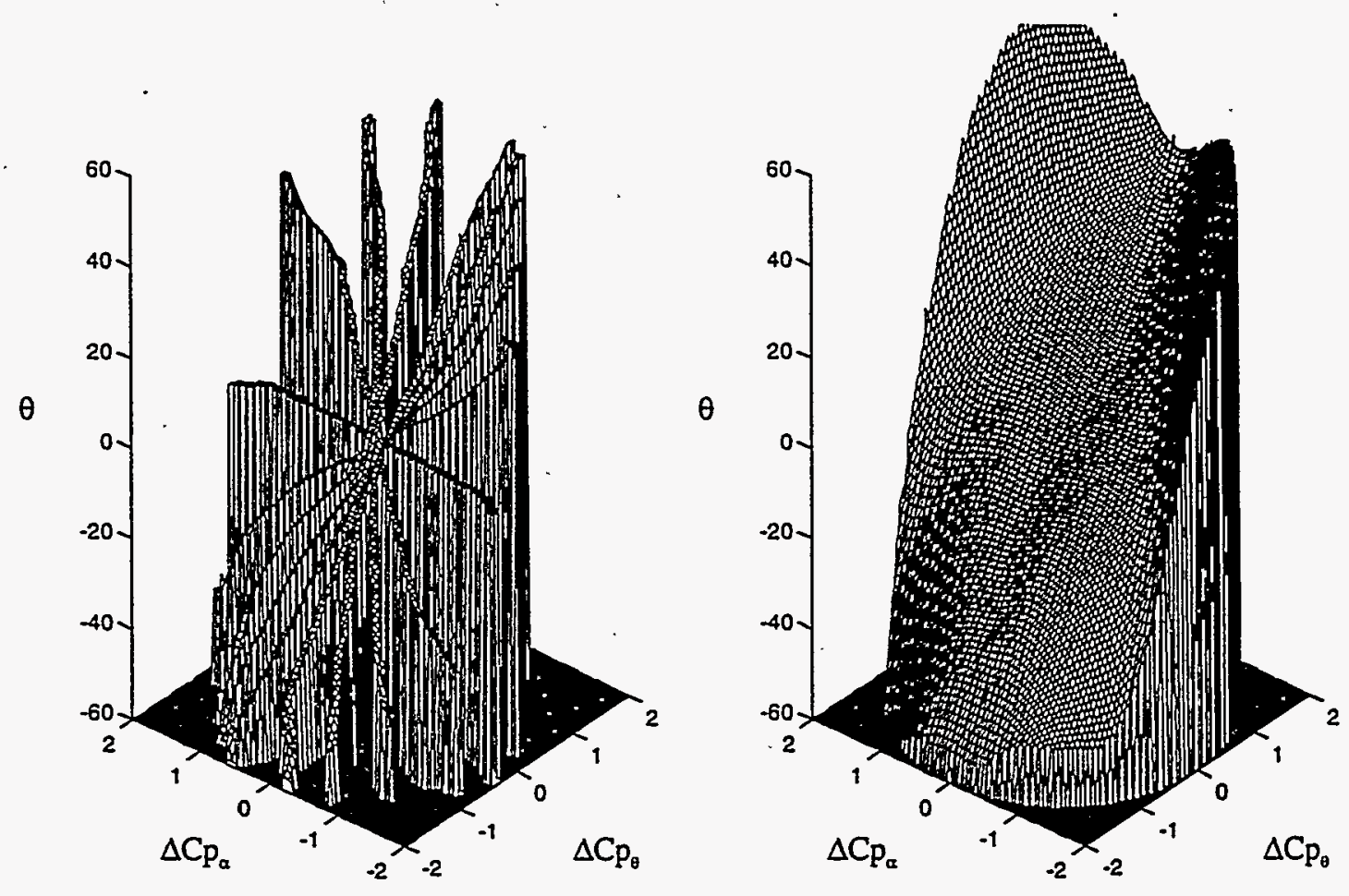

Figure 6 - Static calibration of cross-flow-angle surface

Several interpolation techniques were used to define the surface contours between calibration points. Most of these methods failed for various reasons. Linear interpolation methods were not applicable because of the non-linear nature of the curves. Bi-cubic spline interpolation failed because of the nature of the data. Each radial location on each curve actually consists of several points in close proximity. This property disturbed the bi-cubic spline method and created bumps at each arm. Eventually, neural-network methods were tested with excellent results.

The particular neural-network method used actually involved 10 networks for each surface. First, the data was randomly sampled, without replacement, into two bins each containing approximately $20 \%$ of the data. Then a two-layer feed-forward neural network with 12 hidden neurons was created and trained on one of the bins. The training method was standard backpropagation using Levenberg-Marquardt optimization implemented on the Matlab software. After each epoch of training, the second set or "testing" set of data was passed forward through the net. The final network used was the one during which the testing set had the least sum-squared error. This was done 10 times for each surface, each with different random samples in the bins and different random initial weights.
The 10 surfaces generated were then averaged together. This technique of "early stopping" and "bootstrapping" permits an honest evaluation of the data that tends to eliminate small anomalies in the overall data set and in each network.

The results of the complete static calibration and associated neural-network fits are shown in Figures $4 \mathrm{~b}$, $5 \mathrm{~b}$ and $6 \mathrm{~b}$. These final calibration curves provide the basis for converting measured 5-hole probe pressure data into $q_{\omega}, \alpha, \theta$ over an operating inflow cone angle of $\pm 40^{\circ}$.

\section{Dynamic Calibration}

In order to test the sensitivity of the calibration curves to unsteady and Reynolds effects, calibration curves were generated for each of the test conditions listed in Table 1. Initially, a strong hysteresis was evident with reduced frequency (Figure 7). Accounting for the phase shift due to pressure tube length eliminated the hysteresis (Figure 8). After examining and correcting each of the dynamic calibration runs for tube length, it was determined that the static probe calibrations were independent of reduced frequency over the frequency range of interest. 


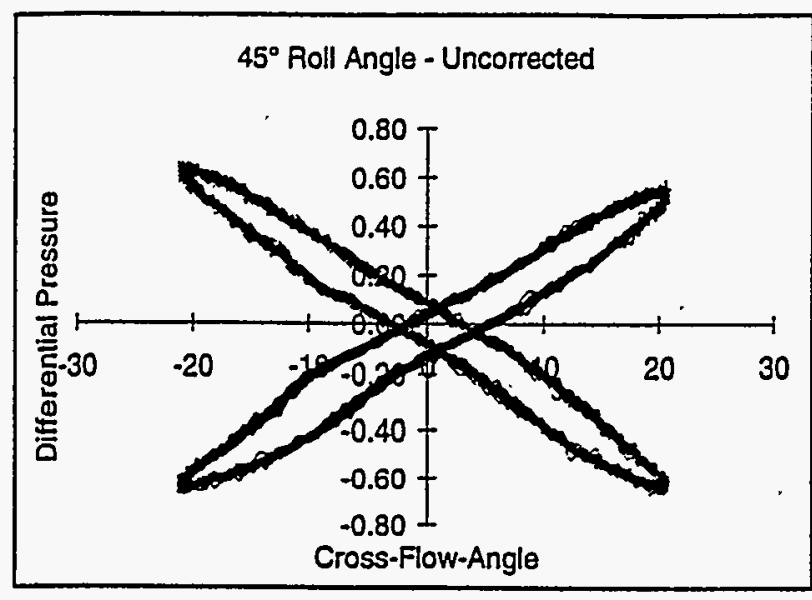

Figure 7 - Hysteresis in differential pressure traces at a high reduced frequency $(\mathrm{k}=0.6)$

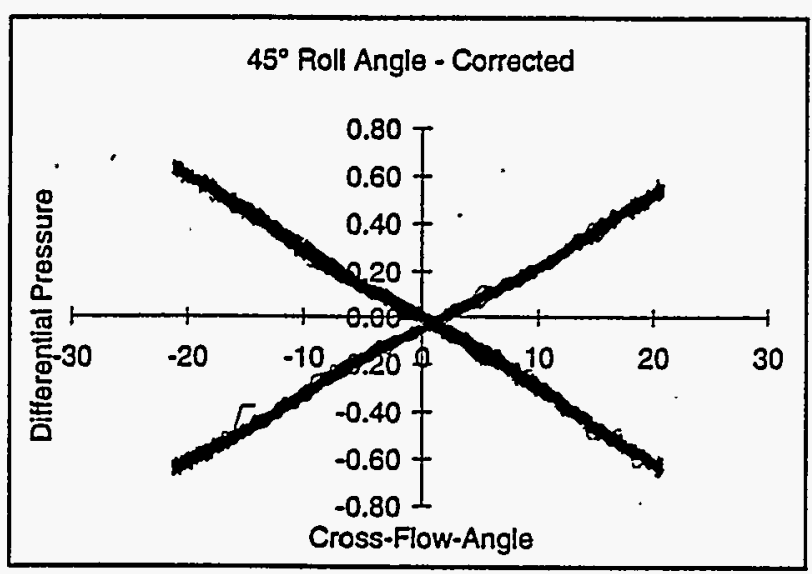

Figure 8 - Hysteresis is eliminated by accounting for pressure tube length.

\section{Data Reduction}

The instantaneous values for $q_{\infty}, \alpha$ and $\theta$ are obtained from the five measured static pitot pressures and the three calibration curves. The process requires two separate steps performed in the following sequence: (1) determination of $q_{\omega}, \Delta C p_{a}$, and $\Delta \mathrm{C}_{\theta}$, with an iterative solution process using the measured center tap pressure and figure $4 \mathrm{~b}$, and (2) obtaining $\alpha$ and $\theta$ directly from the calibration curves (figure $5 b, 6 b$ ) using the values for $\Delta C \mathrm{p}_{\alpha}$ and $\Delta C \mathrm{p}_{\theta}$ obtained in step 1 .

Obtaining an iterative solution for $\mathrm{q}_{\ldots}, \Delta \mathrm{Cp}_{\alpha}$, and $\Delta \mathrm{Cp}_{\theta}$ in step 1 is the most time-consuming. The iteration sequence is outlined in the following steps:
1). $\quad \mathrm{q}_{-} \mathrm{i}=\left[\mathrm{pl}-\mathrm{p}_{-}\right]$
(Initial assumption, $\mathrm{i}=1$ )
2). $\quad C p_{c} \mathrm{i}=1.0$
(Initial assumption, $\mathrm{i}=1$ )
3). Calculate $\Delta C p_{a}$ and $\Delta C p_{\theta}$ using $q_{m i}$
4). $\quad \operatorname{Read} \mathrm{Cp}_{\mathrm{c} \text { new }}$ from tigure $4 \mathrm{~b}$.

$$
\begin{array}{ll}
\text { 5). } & \Delta C p_{c}=C p_{c i}-C p_{c} \text { new } \\
\text { 6). } & C p_{i+1}=C p_{c i}+(1 /(i+2)) \Delta C p_{c} \\
\text { 7). } & q_{-i+1}=\left[p 1-p_{-}\right] / C p_{i+1} \\
\text { 8). } & \text { Iterate on } i(i=i+1)
\end{array}
$$

Steps 3 through 7 are repeated until one of the following criteria is met:

$$
\begin{aligned}
& \text { 1). } \quad\left|C p_{i}-C p_{i+1}\right| \leq 0.001 \text { or } \\
& \text { 2). } \quad \text { i }>100
\end{aligned}
$$

On average, convergence was obtained within 5 iterations.

\section{$\underline{\text { Results }}$}

The Unsteady Aerodynamics Experiment, instrumented with four custom-built flow-angle flags and one 5-hole pressure probe, was tested in the field at the National Wind Technology Center. A comparison of a flag located at $80 \%$ of span and the 5 -hole probe at $91 \%$ span is shown in Figure 9. Results from an analytical model which calculated angle-of-attack based on diskaveraged inflow conditions and turbine geometry is also plotted for reference. The dip in angle-of-attack at $180^{\circ}$ occurs when the turbine blade rotates into the wake shadow behind the tower. The flag probe responds late to the tower shadow because of its poor frequency response. In contrast, the 5-hole was not frequency limited and the values for $\alpha$ match the analytic model. Note also that the flag oscillates after the tower shadow perturbation. This frequency corresponds to the natural frequency response of the mechanical flag probe.

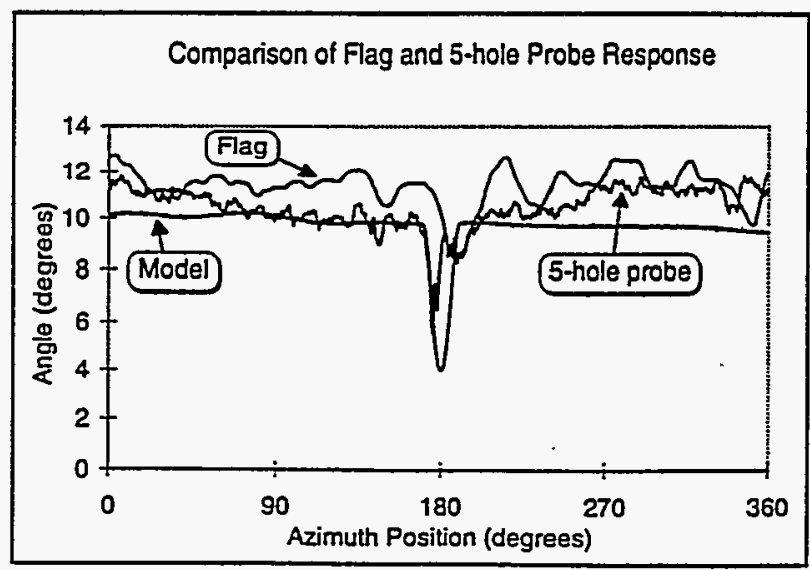

Figure 9 - Comparison of flag and 5-hole probe to a simple analytical model.

\section{Conclusions}

After numerous comparisons, the 5-hole probe was shown to be far superior to the flag probe for measuring 
local flow angle on a wind turbine. It provided high frequency capability without the oscillations or other problems associated with the mechanical flag probe. Additionally, it resolved the 3-D inflow velocity vector providing a complete quantification of the local turbine blade inflow condition.

The probe has also proven to be a robust device in the hostile turbine operations environment. As a result, the Unsteady Aerodynamics Experiment has recently been instrumented with five such probes, each calibrated in the manner described above. With high-resolution angle-of-attack data, it will now be possible to resolve 3-D unsteady separated flow events experienced by turbines in field operation as well as gain some insight into 3-D rotational flow effects.

\section{Acknowledgment}

The U. S. Department of Energy is credited for its funding of this document through the National Renewable Energy Laboratory under contract number DE-AC36-83CH10093.

\section{$\underline{\text { References }}$}

${ }^{1}$ Robinson, M. C., Luttges, M. W., Miller, M. S., Shipley, D. E., Young, T. S. "Wind Turbine Blade Aerodynamics: the Combined Experiment." Presented at Windpower 93, San Francisco, California, July 1216, 1993.

2 Robinson, M. C., Luttges, M. W., Miller, M. S., Shipley, D. E., Young, T. S. "Wind Turbine Blade Aerodynamics: the Analysis of Field Test Data." Presented at ASME/ETCE Wind Energy Symposium, New Orleans, Louisiana, January 23-26, 1994.

${ }^{3}$ Shipley, D. E., Miller, M. S., Robinson, M. C. "Dynamic Stall Occurrence on a Horizontal Axis Wind Turbine Blade." Presented at 14th ASME/ETCE Wind Energy Symposium, Houston, Texas, January 29February 1, 1995.

4 Shipley, D. E., Miller, M. S., Robinson, M. C., Luttges, M. W., Simms, D. A. "Evidence That Aerodynamic Effects, Including Dynamic Stall, Dictate HAWT Structure Loads and Power Generation in Highly Transient Time Frames." Presented at Windpower 94, Minneapolis, Minnesota, May 9-13, 1994.

${ }^{5}$ Fingersh, L. J., Simms, D. A., Butterfield, C. P., Jenks, M. D., "An Overview of the Unsteady Arodynamics Experiment Phase III Data Acquisition System and
Instrumentation", Presented at 14th ASME/ETCE Wind Energy Symposium, Houston, Texas, January 29February 1, 1995. 